This is the author's final, peer-reviewed manuscript as accepted for publication. The publisher-formatted version may be available through the publisher's web site or your institution's library.

\title{
Requirements for a test to evaluate bread-making performance
}

Finlay MacRitchie

\section{How to cite this manuscript}

If you make reference to this version of the manuscript, use the following information:

MacRitchie, F. (2014). Requirements for a test to evaluate bread-making performance. Retrieved from http://krex.ksu.edu

\section{Published Version Information}

Citation: MacRitchie, F. (2014). Requirements for a test to evaluate bread-making performance. Journal of Cereal Science, 59(1), 1-2.

Copyright: ( 2013 Elsevier Ltd.

Digital Object Identifier (DOI): doi:10.1016/j.jcs.2013.11.001

Publisher's Link:

http://www.sciencedirect.com/science/article/pii/S0733521013001781?via=ihub

This item was retrieved from the K-State Research Exchange (K-REx), the institutional repository of Kansas State University. K-REx is available at http://krex.ksu.edu 


\section{Requirements for a test to evaluate bread-making performance}

One of the aims in cereal science research has been to develop procedures for measuring bread-making potential of wheat flours without the necessity of carrying out a standard baking test. The requirements for such tests are that they economize on the time needed and that they correlate well with the baking test. A test that complies with those requisites would be valuable for evaluation of baking potential in breeding programs at an early generation stage. It could also be used to optimize the effects of formulation and process changes in test bakeries.

Some instruments that have been used in test bakeries include the Brabender farinograph and extensigraph and the Chopin alveograph. Both the extensigraph and alveograph have been standard instruments in cereal laboratories for many years. They measure load-deformation properties of developed doughs under specified conditions. Although they do not measure fundamental rheological parameters, they have nevertheless provided useful guides for assessing dough physical properties suitable for specific end uses.

Bread-making essentially involves the creation of a dispersion of small gas bubbles in a dough, followed by a procedure (e.g. fermentation) to make the bubbles expand and the dough to inflate and finally, heating to make the structure set. The bread-making quality of the flour used is then determined by parameters such as the final volume and texture of the loaf. How well the dough expands thus should depend on its capacity to undergo biaxial extension (related to extensibility) and resist collapse (related to alveograph tenacity) in response to the pressure differential in the gas bubbles. There has thus been a logical expectation that final loaf volume and texture should be explained on the basis of the rheological properties of the dough. This expectation has not, however, usually been realized (e.g. Khattak et al., 1973).

The reason for the failure to establish a strong relationship between loaf volume and dough rheological properties has been clarified as a result of the work of Gan et al. (1990). Based on electron micrographs of fermenting dough, it was shown that, at a certain stage, the gluten-starch matrix surrounding the gas bubbles may become discontinuous but yet the gas bubbles continue to grow. This was explained by the presence of liquid lamellae that envelope the gas cells and stabilize them. Thus, gas bubbles in an expanding dough are stabilized by two mechanisms. The primary mechanism is provided by the viscoelastic gluten-starch matrix with liquid lamellae enveloping the gas cells providing a secondary stabilizing mechanism.

The gluten-starch matrix acts at all stages of the dough expansion. The secondary mechanism is not relevant in the early stages of expansion but becomes critical when the gas bubbles first come into contact. If the gas cells are spherical and of uniform size, it can be shown that contact will occur when the relative dough volume reaches a value of 3.85 (Bloksma, 1990). Relative dough volume is here defined as the total volume of the dough divided by the volume of dough devoid of gas. If the gas cells are not uniform in size, the relative volume may reach a higher value than 3.85 before contact but not by very much. The value of 3.85 corresponds to an advanced stage of dough proofing. At the end of proofing, the relative volume is usually between 4 and 5 while, at the end of oven spring, it should be between 5 and 7 (Bloksma, 1990). After gas bubbles come into contact, subsequent dough expansion causes distortion from their spherical shape. Thus, in evaluating bread texture, good quality is associated with elongated gas cells. It is sometimes found that dough 
samples expand normally until the end of the proofing stage but fail to expand further after placing in the oven. This is not necessarily due to effects of heating in the oven. It may simply correspond to the stage where the secondary stabilizing mechanism begins to operate (i.e. when gas bubbles come into contact). If the liquid lamellae have no stability, then the limiting expansion capacity of the dough is reached and the gas cells rupture.

A report by MacRitchie and Gras (1973) showed that variations in the natural lipid composition of flours caused large differences in loaf volume for a given dough, yet alveograms were not significantly different. The explanation for these observations is that the alveograph measurements relate to dough bulk rheological properties whereas lipids, being surface active compounds, adsorb at the air/aqueous interface of films (lamellae) that surround the gas bubbles and influence their stability.

Experiments to distinguish between the two stabilizing mechanisms have been described by Sroan et al (2009) and Sroan and MacRitchie(2009). In the first paper, the rheological properties of doughs from a particular flour were varied by altering the molecular weight distribution of its gluten protein. Strain hardening index was shown to be a key rheological property for stabilizing the gluten-starch matrix as has been established by the work of van Vliet et al (1992) and Dobraszczyk and Roberts (1994). In the second paper, large changes in bake-test loaf volume were produced by varying the lipid composition of the flour. There was no change in dough rheological properties, confirming that lipids were exerting their effects on the secondary stabilizing mechanism (the liquid lamellae).

It is evident then, that a method for simulating the bread-making process must be one that recognizes both stabilizing mechanisms. The alveograph, although purporting to relate to the bread-making process by using biaxial extension, does not measure anything more than parameters related to the rheological properties of the dough An instrument that only gives information about the bulk rheological properties of the dough cannot be expected to predict bread-making performance reliably. Investigation of the secondary stabilizing mechanism requires a system consisting of numerous gas bubbles interacting with each other. A test that does fulfil the requirements is that of dough expansion by application of low pressure, described by Gandikota and MacRitchie (2005). In this method, a developed dough is placed in a chamber and subjected to a low pressure, causing it to inflate until it reaches a maximum volume when gas cells rupture and the structure fails. If the same baking pans are used, the shape of the inflated dough is the same as that attained in a baking test. A dough height measurement can then be converted to a volume by a previous calibration.

The dough expansion test appears to satisfy the requirements for a test to evaluate bread-making performance - economy of time and a high correlation with the baking test. The longest step in the process is the development of the dough (normally by mixing). Transfer of the tinned dough to the vacuum chamber, application of the low pressure and recording of the height takes only a few minutes. The simplicity of the process suggests that it could be developed as a semi-automatic procedure with a high throughput. Preliminary measurements showed a high correlation between dough height and baked loaf volume (Gandikota and MacRitchie, 2005).

An advantage of the dough expansion test over other routine tests that have been used is that the same dough formulation can be used as in the baking test. A possible concern is that it does not incorporate the intermediate punching and molding 
steps that are used in long fermentation baking tests and which have been shown to have substantial effects on the final result. However, rather remarkably, the maximum dough height reached in the expansion test appeared to be unaffected by the stage in the fermentation process when it was applied (Gandikota and MacRitchie, 2005). This suggests that, provided the negative pressure applied is above a certain value, the expansion capacity of a specific dough (measured by the dough height) is a fundamental parameter that is determined at the end of dough development and is unaffected by subsequent manipulation of the gas cell structure.

Scientific research has advanced our understanding of the processes involved in bread-making. Companies who manufacture instruments for use in cereal laboratories have strongly supported the cereal industry by supplying useful equipment. It is to be hoped that these companies will make use of the new knowledge in order to introduce laboratory methods for evaluating bread-making quality in a more objective way than is presently done.

\section{References}

Bloksma, A.H. 1990. Dough structure, dough rheology and baking quality. Cereal Foods World 35, 237-244.

Dobraszczyk, B.J., Roberts, C.A. 1994. Strain hardening and dough gas cell-wall failure in biaxial extension. Journal of Cereal Science 20, 265-274.

Gan, Z., Angold, R.E., Williams, M.R., Ellis, P.R., Vaughan, J.G., Galliard, T. 1990. The microstructure and gas retention of bread dough. Journal of Cereal Science 12, 15-24.

Gandikota, S., MacRitchie, F. 2005. Expansion capacity of doughs: methodology and application. Journal of Cereal Science 42, 157-163.

Khattak, S., D’Appolonia, B.L., Banasik, O.J. 1974. Use of the alveograph for quality evaluation of hard spring wheat. Cereal Chemistry 51, 355-363.

MacRitchie, F., Gras, P.W. 1973. The role of flour lipids in baking. Cereal Chemistry 50, 292-302.

Sroan, B.S., Bean, S.R., MacRitchie, F. 2009. Mechanism of gas cell stabilization in breadmaking. I. The primary gluten-starch matrix. Journal of Cereal Science 49, 32-40.

Sroan, B.S., MacRitchie, F. 2009. Mechanism of gas cell stabilization in breadmaking. II. The secondary liquid lamellae. Journal of Cereal Science 49, 41-46.

Van Vliet, T., Jansen, A.M., Bloksma, A.H., Walstra, P. 1992. Strain hardening of dough as a requirement for gas retention. Journal of Texture Studies 29, 227234.

Finlay MacRitchie

Department of Grain Science and Industry

Kansas State University

Manhattan, Kansas , U.S.A. 